\title{
Viral aetiologies of acute encephalitis in a hospital-based South Asian population
}

\author{
Janarthani Lohitharajah', Neelika Malavige ${ }^{2}$, Carukshi Arambepola ${ }^{3}$, Jithangi Wanigasinghe ${ }^{4}$, Ranjanie Gamage ${ }^{5}$, \\ Padma Gunaratne ${ }^{5}$, Pyara Ratnayake ${ }^{6}$ and Thashi Chang ${ }^{7^{*}}$ (D)
}

\begin{abstract}
Background: The aetiological spectrum of acute encephalitis shows inter- and intra-geographical variations. We aimed to identify the viruses that cause infectious encephalitis in Sri Lanka, which represents a South Asian population.

Methods: A cross-sectional study was conducted among 99 patients with encephalitis/meningoencephalitis admitted to two tertiary-care hospitals in Colombo. Cerebrospinal fluid and serum were tested for conventional and emerging encephalitogenic viruses. Specific nucleic acid amplification and antibody assays were used to identify viruses. Plaque reduction neutralization test was done to confirm the diagnosis of West Nile virus (WNV).

Results: Patients' age ranged from 1 month to 73 years (mean $=24.91$; SD $=21.33$ ) with a male:female ratio of 1. 75:1. A viral aetiology was identified in only $27.3 \%$. These included dengue virus (40.7\%), Japanese encephalitis virus (25.9\%), varicella zoster virus, WNV and probable Epstein Barr virus (11.1\% each). None were positive for herpes simplex viruses or cytomegalovirus. Screening for bacterial aetiologies was negative for all patients. There were no distinguishable clinical or laboratory findings between the different viral aetiologies. The case fatality rate was 7\%, which was higher among patients with an identified viral aetiology.
\end{abstract}

Conclusions: A viral aetiology was identified in only about a quarter of patients with encephalitis. Dengue virus accounted for the majority.

Keywords: encephalitis, virus, Sri Lanka, South Asia, dengue, WNV

\section{Background}

Encephalitis denotes inflammation of the brain parenchyma that clinically manifests with the syndrome of fever, headache, altered cognition, seizures and focal neurological dysfunction leading to significant mortality and permanent neurological sequelae worldwide [1]. Often the inflammation extends into the meninges causing additional features of meningism and the combined syndrome of meningoencephalitis. The causes of encephalitis are diverse, but broadly categorised as infectious and autoimmune. Viruses are the most commonly identified aetiology of the infectious agents [2], but in up to $70 \%$ of cases the cause remains unidentified [3]. However, the recent recognition of several autoimmune encephalitides

\footnotetext{
* Correspondence: thashichang@gmail.com

${ }^{7}$ Department of Clinical Medicine, Faculty of Medicine - University of

Colombo, 25, Kynsey Road, Colombo 00800, Sri Lanka

Full list of author information is available at the end of the article
}

and use of rigorous diagnostic testing algorithms have substantially decreased the proportion of unknown causes of encephalitis [4].

Of the viruses, herpes simplex virus type 1 (HSV1) is reportedly the commonest cause of adult sporadic encephalitis while varicella zoster virus (VZV) account for most of paediatric encephalitis in developed countries $[5,6]$. However, numerically Japanese encephalitis (JE) is the most important global cause of encephalitis causing an estimated 30,000-50,000 cases and about 15,000 deaths annually [7], while West Nile virus (WNV) is the most widespread virus encountered in parts of North America, Europe, Russia, Africa, the Middle East, Indonesia and India [8]. Apart from the established encephalitic viruses, recent studies have identified many emerging encephalitic viruses such as Chandipura and Nipah viruses, particularly in South Asia $[9,10]$. However, in Sri Lanka, which is a tropical island positioned 
between northern latitudes $5^{\circ}$ and $10^{\circ}$, the aetiological spectrum of viral encephalitis remains unknown because acute encephalitis surveillance has been confined to JE. This study aimed to identify the viruses causing encephalitis in Sri Lanka to add to the spectrum of encephalitic viruses being identified in South Asia.

\section{Methods}

\section{Patients and samples}

Using a cross-sectional study design, consecutive patients with a clinical syndrome of encephalitis/meningoencephalitis admitted to the two largest tertiary-care hospitals in Sri Lanka for adults (National Hospital of Sri Lanka, bed-strength 3900) and children (Lady Ridgeway Hospital for Children, bed-strength 900) between November 2012 and August 2014 were recruited. The syndrome of encephalitis/meningoencephalitis was defined based on the Consensus Statement of the International Encephalitis Consortium [11] as depressed or altered level of consciousness, change in behaviour or personality lasting for $\geq 24 \mathrm{~h}$ and requiring hospitalization for one or more of the following symptoms: fever, seizures or focal neurological dysfunction. Patients with an alternative diagnosis that could mimic encephalitis such as psychiatric illness, metabolic disorders, epilepsy, post-anoxia, vasculitis, stroke and septicaemia, and patients in whom lumbar puncture was contraindicated were excluded. Diagnosis of encephalitis was made by a Board-certified specialist in Neurology, Paediatric Neurology, Internal Medicine or Paediatrics. The computed minimum sample size to achieve a precision of 0.05 and $Z_{\alpha}$ value of 1.96 was 87. Written informed consent was obtained from either the patient or guardian. Serum and/or cerebrospinal fluid (CSF) were obtained from all patients when these specimens were collected as part of their diagnostic work up. Demographic, clinical and laboratory data including CSF analysis, blood counts, brain imaging and electroencephalogram (EEG) results were recorded. The paediatric age group was defined as less than 12 years.

\section{Laboratory analysis}

PCR assays were performed for EBV, CMV, VZV, HSV, WNV, JEV and dengue while IgM and IgG antibody tests were performed for HSV, JEV, WNV and dengue in serum and CSF (when available) in all patients $(n=99)$.

\section{Nucleic acid extraction}

Nucleic acid was extracted from $200 \mu \mathrm{l}$ (for DNA) and $140 \mu \mathrm{l}$ (for RNA) of clinical specimens (blood/serum, CSF) using the spin protocol of QIAamp DNA mini blood kit (QIAGEN ${ }^{\circ}$ ) and QIAamp viral RNA mini kit $\left(\mathrm{QIAGEN}^{\circ}\right)$ and stored at $-80{ }^{\circ} \mathrm{C}$ until further analysis. For DNA extraction from CSF carrier DNA, poly dA (Promega, USA) was used.

\section{$P C R$ and $R T-P C R$ analysis}

Polymerase chain reaction (PCR) was used to detect DNA viruses such as herpes simplex virus type 1 (HSV-1) and type 2 (HSV-2), varicella zoster virus (VZV), Epstein Barr virus (EBV) and cytomegalovirus (CMV). Reverse transcriptase polymerase chain reaction (RT-PCR) was used to detect RNA viruses such as dengue and Japanese encephalitis virus. For primers used and their target genes see Additional file 1.

\section{$P C R$}

DNA samples were amplified in a $50 \mu \mathrm{l}$ PCR reaction as previously described [12-15]. DNA extracted from clinical specimens of patients who were known to be having acute infections of herpes simplex, varicella, CMV and EBV were used as positive controls and deionised water was used as negative control.

\section{$R T-P C R$}

RNA samples were amplified in a $50 \mu \mathrm{RT}$-PCR reaction mixture as previously described [16]. RNA extracted from serum of dengue infected patients and RNA from JE vaccine were used as positive controls for dengue and JE RT-PCR, respectively. Deionized water was used as negative control. PCR products were separated on $2 \% w / v$ agarose (Promega) in 1 TAE buffer.

\section{ELISA}

Enzyme-linked immunosorbant assays (ELISA) were used to detect specific immune reactions utilizing IgM capture ELISA for HSV-1, HSV-2 (Abcam, UK), dengue (Panbio), JEV (InBiOS, USA), WNV (InBiOS, USA) and IgG capture ELISA for HSV-1, HSV-2 (Abcam,UK) and Dengue virus (Panbio). Dengue NS1 antigen was also tested (dengue early ELISA, Panbio). The results were interpreted according to the manufacturer's instructions.

\section{Bacterial screening}

CSF Gram stain, culture and blood cultures were performed to exclude bacteriological infection. Tuberculosis is notoriously difficult to isolate in central nervous system disease. However, this was excluded based on the clinical syndrome, inflammatory markers, neuroimaging and CSF profiles and staining for acid fast bacilli, and when indicated, culture and PCR for Mycobacterium tuberculosis.

\section{Confirmatory test}

Plaque reduction neutralization test (PRNT) was done at the National WNV reference laboratory of the National University of Singapore only for samples that were positive for WNV-specific IgM. 


\section{Definitions for diagnosis}

JEV encephalitis was diagnosed as definite if RT-PCR for JEV was positive or if JEV-specific IgM was detected in CSF and the ISR value for JEV-specific IgM was over two-fold more than the IgM index value for dengue and ISR value for WNV.

Dengue encephalitis was diagnosed as definite if RTPCR for DENV was positive or if DENV-specific IgM was detected in CSF. Dengue encephalitis was considered probable if DENV-specific IgM was not detected in CSF, but detected only in serum.

WNV encephalitis was diagnosed as definite if WNVspecific IgM was detected in CSF and WNV neutralizing antibodies were detected on PRNT.

VZV encephalitis was diagnosed as definite if VZVPCR was positive in CSF or in serum. EBV encephalitis was diagnosed as probable if EBV-specific DNA was detected in CSF since EBV-specific antibody tests were not performed to differentiate between acute and reactivated infection.

\section{Ethical considerations}

The study was approved by the Ethics Review Committees of the Faculty of Medicine, University of Colombo, Sri Lanka and that of the two hospitals. Informed written consent was obtained from the patient, or from the guardian in the case of mentally incompetent patients or children. None refused consent to participate.

\section{Results}

A total of 108 patients were recruited over a period of 21 months, but 9 were subsequently excluded due to inadequate clinical material for analysis. Patients' age ranged from 1 month to 73 years $($ mean $=24.91 ; \mathrm{SD}=21.33$ ) with $41.4 \%$ being less than 12 years. The male to female ratio was $1.75: 1$ in both adults and children. Patients were residents from 16 of the 25 administrative districts in Sri Lanka. Most cases peaked during the months of January/February and May/June consistent with the temporal pattern of encephalitis noted in Sri Lanka (Fig. 1).

The clinical and laboratory characteristics of patients are shown in Table 1. Brain imaging had been performed with computerised tomography (CT) in 59 patients and magnetic resonance imaging (MRI) in 31 patients. Abnormalities were noted in $65.5 \%$ of CT scans and $67.8 \%$ of MRI scans. The most common of the neuroimaging abnormalities was focal or generalised cerebral oedema $(76.9 \%)$ on $\mathrm{CT}$ followed by focal cerebritis (36.8\%), cerebral infarction (21.1\%) and meningeal enhancement $(15.8 \%)$ on MRI. None of the imaging abnormalities were specific to any of the identified virus types. EEGs had been done in 33 patients and were abnormal in $72.4 \%$.

A viral aetiology was identified in only $27.3 \%$, more among adult (38\%) than paediatric patients (12.2\%). Results of viral detection using IgM capture ELISA and PCR are shown in Table 2. The viral aetiologies identified included dengue virus (40.7\%), JE virus (25.9\%), VZV (11.1\%) and WNV (11.1\%). Two of the three patients positive for WNV specific IgM were tested for PRNT50 neutralizing antibodies and were found to have titres of 800 against WNV confirming definite WNV infection. Since EBV was detected only by PCR of CSF without serological confirmation, its role as an aetiological agent was considered probable and not definite (see 'Definitions' above). None of the patients were positive for HIV.

There were no distinguishable clinical or laboratory characteristics between the different viral aetiologies (Table 3). Although dengue fever is characterised by fever and thrombocytopenia, which can be complicated by extravascular fluid leakage, haemorrhage and hepatitis, among patients with dengue virus encephalitis, only

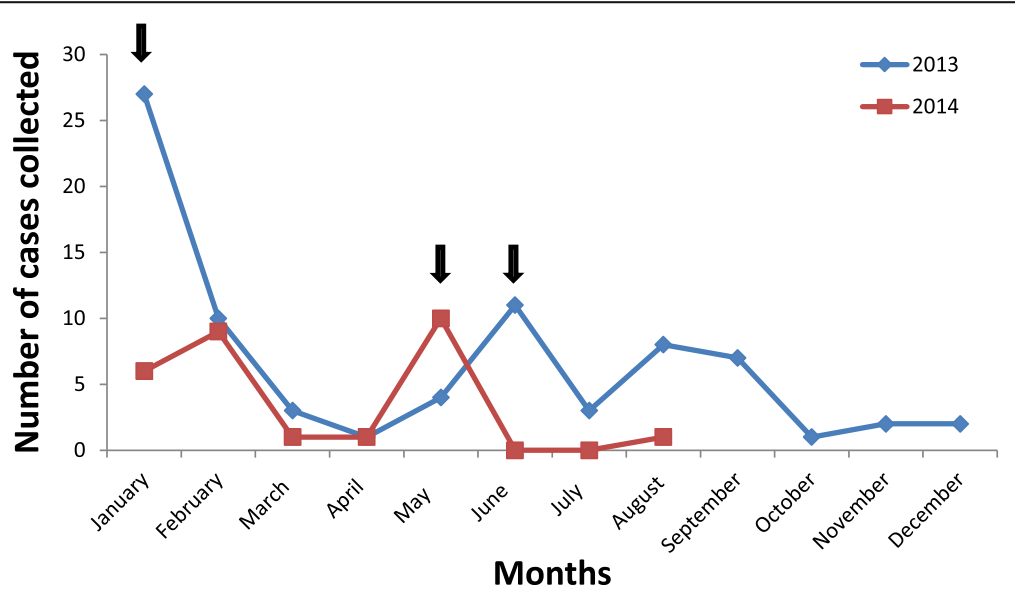

Fig. 1 Temporal distribution of cases of encephalitis recruited during the study period. Arrows indicate peak periods of highest frequencies 
Table 1 Clinical and laboratory characteristics of patients with encephalitis

\begin{tabular}{lc}
\hline Clinical / laboratory characteristic & Number of patients (of $n=99$ ) \\
\hline Altered level of consciousness & 99 \\
Fever & 93 \\
Headache & 54 \\
Seizures & 58 \\
Prodromal symptoms & 77 \\
Focal neurological signs & 44 \\
Cerebellar signs & 12 \\
Extrapyramidal signs & 6 \\
Neuropsychiatric symptoms & 21 \\
Cerebrospinal fluid & \\
Protein $>40$ mg/dl & 22 \\
CSF:plasma glucose ratio $<30 \%$ & 39 \\
Pleocytosis & 26 \\
Gram stain positivity & 0 \\
Bacterial culture positivity & 0 \\
\hline
\end{tabular}

4 of 11 had thrombocytopenia while none had evidence of fluid leakage, haemorrhage or hepatic necrosis. Seven patients with dengue virus encephalitis developed seizures. Four of 7 patients with JE developed extrapyramidal features and neuropsychiatric manifestations. None of the other aetiologies manifested extrapyramidal features. Only 1 of the 3 patients with WNVE had CSF neutrophil pleocytosis. Two of the three patients with VZV encephalitis developed seizures while one had features of cerebellitis, but none developed a skin rash. All three patients with probable EBV encephalitis developed seizures while one had periodic lateralising epileptiform discharges on EEG.

The mean duration of hospital stay was 15 days (SD 12.5; range 2-90). All patients were treated with intravenous aciclovir and varying courses of antibiotics

Table 2 Viruses identified in serum and/or CSF using polymerase chain reaction and IgM capture ELISA

\begin{tabular}{lccc}
\hline Viruses & \multicolumn{2}{l}{$\begin{array}{l}\text { Number of patients positive } \\
\text { of 99 tested }\end{array}$} & Total \\
\cline { 2 - 3 } & PCR / RT-PCR & IgM - ELISA & \\
\hline Varicella zoster virus & 03 & ND & 03 \\
Epstein Barr virus & 03 & ND & 03 \\
Cytomegalovirus & 00 & ND & 00 \\
Herpes simplex types 1 and 2 & 00 & 00 & 00 \\
Japanese encephalitis virus & 00 & 07 & 07 \\
Dengue virus & 00 & 11 & 11 \\
West Nile virus & 00 & 03 & 03 \\
Total & 06 & 21 & 27 \\
\hline
\end{tabular}

ND Not Done and steroids. Death occurred in six adults and one child resulting in a case fatality rate of $7 \%$ in this study. The mortality rate was higher among patients in whom a viral aetiology was identified (5/27) than in patients in whom an aetiology was not identified (2/72) (Table 3). This difference was statistically significant $(p<0.05)$.

\section{Discussion}

Despite a wide array of stringent laboratory testing, a viral aetiology was identified in only just over a quarter of patients presenting to hospital with a syndrome of encephalitis/meningoencephalitis. Dengue virus accounted for $41 \%$ while Japanese encephalitis accounted for $26 \%$. We identified three patients with WNV neuroinvasive disease. This was the first identification of human WNV in Sri Lanka, which was reported by us earlier because of its public health implications [17]. It is likely that a proportion of 'virus-negative' patients had autoimmune encephalitis or encephalitis due to emerging viruses or viruses not tested in our study.

In Sri Lanka, surveillance of encephalitis is confined to JE, which has been endemic for several decades and caused epidemics in the mid and late 1980s [18]. However, JE accounts for only $39 \%$ of all notified cases of acute encephalitis in Sri Lanka (Epidemiological Bulletin 2012, Epidemiology Unit, Sri Lanka), and the aetiological spectrum of viral encephalitis has remained unknown. Given that HSV and VZV have been reported as the commonest viral aetiologies of encephalitis in developed countries, it has been usual practice to administer intravenous aciclovir to all patients presenting with suspected infectious encephalitis in Sri Lanka. However, none in our study was positive for HSV. This may have been partly related to the low HSV seroprevalence in Sri Lanka. For example, the HSV-1 seroprevalence was $74.4 \%$ among individuals aged 35 to 40 years who attended sexually transmitted diseases clinics in Sri Lanka compared to a seroprevalence of over $90 \%$ in the general population in most other countries [19], and partly related to the timing of specimen collection, since it has been observed that the yield of PCR for HSV is less during the first 3 days and after 10-14 days of disease onset [20]. For this reason, and because we detected VZV sans skin manifestations in our study, we would recommend continuing the practice of empirical intravenous aciclovir in acute encephalitis unless an alternative aetiology is evident.

Dengue virus is endemic in Sri Lanka and has emerged as the most important vector-borne disease causing recurrent epidemics [21]. Dengue is recognized as a frequent or leading cause of encephalitis in endemic regions and dengue encephalitis may be the primary manifestation of infection [22, 23]. Given that there were 32,063 cases of dengue reported in Sri Lanka during the period that this study was conducted, it is not surprising that dengue has 
Table 3 Clinical and laboratory characteristics of patients with encephalitis according to aetiological diagnosis

\begin{tabular}{|c|c|c|c|c|c|c|c|c|c|c|}
\hline $\begin{array}{l}\text { Encephalitis } \\
\text { aetiology }\end{array}$ & Seizures & $\begin{array}{l}\text { Focal neurological } \\
\text { signs }\end{array}$ & $\begin{array}{l}\text { Neck } \\
\text { stiffness }\end{array}$ & Headache & $\begin{array}{l}\text { Neuro-psychiatric } \\
\text { features }\end{array}$ & $\begin{array}{l}\text { Extra-pyramidal } \\
\text { features }\end{array}$ & $\begin{array}{l}\text { Cerebellar } \\
\text { signs }\end{array}$ & $\begin{array}{l}\text { Thrombo } \\
\text { cytopaenia }\end{array}$ & $\begin{array}{l}\text { CSF } \\
\text { pleocytosis }\end{array}$ & Outcome \\
\hline $\mathrm{DV} 1$ & - & - & + & + & - & - & - & - & Lymphocytic & Discharged \\
\hline DV2 & - & - & - & + & - & - & - & + & None & Discharged \\
\hline DV3 & - & - & + & + & - & - & - & - & None & Discharged \\
\hline DV4 & + & + & + & - & - & - & - & - & None & Death \\
\hline DV5 & + & - & - & + & - & - & - & + & None & Death \\
\hline DV6 & + & + & - & - & - & - & - & + & None & Discharged \\
\hline DV7 & + & - & + & + & - & - & - & - & None & Discharged \\
\hline DV8 & + & - & + & + & - & - & - & - & Lymphocytic & Discharged \\
\hline DV9 & + & + & - & - & - & - & - & - & None & Discharged \\
\hline DV10 & + & - & - & - & Abnormal behaviour & - & - & - & None & Discharged \\
\hline DV11 & - & + & - & - & - & - & - & + & None & Discharged \\
\hline JE1 & + & + & - & - & Hallucination & + & - & - & None & Discharged \\
\hline JE2 & - & + & + & + & - & - & - & - & ND & Death \\
\hline JE3 & - & + & + & - & - & - & - & - & Lymphocytic & Discharged \\
\hline JE4 & - & + & + & + & Aggressive & + & - & - & None & Discharged \\
\hline JE5 & - & - & + & - & Hallucination & - & - & - & None & Discharged \\
\hline JE6 & - & + & - & + & Hallucination & + & - & - & None & Discharged \\
\hline JE7 & + & + & + & - & - & + & - & - & None & Discharged \\
\hline WNV1 & + & - & - & - & - & - & - & - & None & Discharged \\
\hline WNV2 & - & - & + & + & - & - & - & - & Neutrophilic & Discharged \\
\hline WNV3 & + & - & + & + & - & - & - & - & Lymphocytic & Discharged \\
\hline VZV1 & + & + & + & - & - & - & + & - & None & Discharged \\
\hline VZV2 & + & - & - & - & - & - & - & - & None & Discharged \\
\hline VZV3 & - & - & - & + & - & - & - & - & Lymphocytic & Discharged \\
\hline EBV1 & + & + & + & + & - & - & + & - & Lymphocytic & Discharged \\
\hline EBV2 & + & + & - & - & - & - & - & - & None & Death \\
\hline EBV3 & + & + & - & - & - & - & - & - & Lymphocytic & Death \\
\hline
\end{tabular}

All patients had altered level of consciousness and fever

DV Dengue virus, JE Japanese encephalitis, WNV West Nile virus, VZV Varicella zoster virus, EBV Epstein Barr virus, $M$ male, $F$ female, CSF cerebrospinal fluid, EEG electroencephalogram, MRI magnetic resonance imaging, CT computerised tomography, ND not done

emerged as the commonest viral aetiology in our study. Although thrombocytopaenia associated with extravascular fluid leakage are highly suggestive of dengue infection in endemic regions, in our study, dengue encephalitis occurred as a primary manifestation of dengue infection with only a third of dengue encephalitis patients developing thrombocytopaenia while none had fluid leakage.

Six of the seven patients with JE were over the age of 20 years. It is likely that none of these patients had been immunised given that immunisation began in a phased basis in 1988 and reached country-wide coverage in only 2011. Flaccid paralysis in the context of encephalitis suggests the aetiologies of JE and WNV. However, none of our patients demonstrated this feature, even among those diagnosed with JE and WNV. Notably, extrapyramidal features were noted in only JE while neuropsychiatric manifestations occurred predominantly also in JE. However, extrapyramidal features and neuropsychiatric manifestations are known to occur in other forms of encephalitis, particularly autoimmune encephalitis [24, 25].

This study resulted in the identification of human WNV in Sri Lanka, which has the requisite environment for the maintenance of the zoonotic WNV life-cycle between the Culex genus of mosquitoes and passerine birds. However, there were no distinguishing clinical characteristics in the WNV infected patients [17]. The presence of neutrophil predominance in CSF has been suggested as a possible diagnostic clue of WNV infection [26], but only one of our three patients had CSF neutrophilic pleocytosis. 
Although VZV had been identified as a common aetiology among paediatric encephalitis in developed countries [5], all $3 \mathrm{VZV}$ patients in our study were adults. It is likely that our patients represented reactivated disease while those reported in developed countries were related to primary infection. Furthermore, compared to developed countries where $95 \%$ of the population are seropositive for VZV at 5 years, in Sri Lanka it is predominantly an adult disease with seroprevalence reaching $50 \%$ at 60 years in rural populations [27]. VZV vaccine in not routinely given to children in Sri Lanka. Moreover, chickenpox has been noted to be more common in adult than paediatric populations in Sri Lanka [28]. Enteroviruses have now superseded VZV as commonest cause of childhood encephalitis in developed countries, likely because of better use of molecular tests, and because of implementation of VZV vaccines [29]. Conspicuously, none of our VZV encephalitis patients manifested a skin rash highlighting primary CNS presentation of the virus.

Chandipura and Nipah viruses have been recognised as emerging viral aetiologies of several outbreaks of encephalitis in South Asia [9, 10] and Chandipura virus has been isolated from toque macaque monkeys in Sri Lanka [30]. Although we did not detect either of these viruses in our study population, these viral aetiologies were not completely excluded since we lacked appropriate positive controls for these viruses in our assays.

The mortality rate was lower among patients with an unidentified aetiology. This may suggest less virulence of agents not screened in our panel of attributable viruses or self-limiting autoimmune aetiologies.

The strengths of our study stems from the inclusion of both paediatric and adult patients admitted to the two largest tertiary referral centres in a relatively small country which facilitates referral of patients to these centres from many parts of the country as reflected by the distribution of our patients. Furthermore, encephalitis is a serious neurological disorder that invariably presents to hospital, which justifies studying a hospital-based population. We used both serology and nucleic acid techniques rigorously in attempting to identify an infectious aetiology. Weaknesses include the lack of appropriate positive controls for assays of Nipah and Chandipura virus detection and the lack of serological confirmation of EBV. Furthermore, our aetiological analysis did not include all viruses that can potentially cause encephalitis and hence, a proportion of patients with a viral aetiology may have been missed. A further weakness was that our study did not include long-term follow-up of patients.

\section{Conclusions}

The causes of infectious encephalitis are many and varied, and accurate diagnosis is necessary for appropriate treatment and accurate prognostication. Our study is consistent with previous observations in the elusiveness of identifying aetiological agents of encephalitis [31], but highlights the need to widen the net to capture emerging agents.

\section{Additional file}

Additional file 1: Primers and their target genes. (DOCX $14 \mathrm{~kb}$ )

\section{Abbreviations}

CMV: Cytomegalovirus; CSF: Cerebrospinal fluid; CT: Computerised tomography; EBV: Epstein Barr virus; EEG: Electroencephalogram; ELISA: Enzyme-linked immunosorbant assay; HSV: Herpes simplex virus; ISR: Immune status ratio; JEV: Japanese encephalitis virus; MRI: Magnetic resonance imaging; PCR: Polymerase chain reaction; PRNT: Plaque reduction neutralization test; RT-PCR: Reverse transcriptase polymerase chain reaction; VZV: Varicella zoster virus; WNV: West Nile virus

\section{Acknowledgements}

Prof Mah Lee Ng and Dr. Anthony Jin Shun Chua of the Department of Microbiology, Yong Loo Lin School of Medicine, National University of Singapore for doing the PRNT to confirm WNV infection.

\section{Funding}

This work was supported by the National Research Council, Sri Lanka (NRC Grant No. 11-75).

\section{Availability of data and materials}

All data generated or analysed during this study are included in this published article [and its Additional files].

\section{Authors' contributions}

TC, NM, CA and JL conceptualised and designed the study. JL collected the data and specimens, and carried out the laboratory analysis of specimens under the supervision of NM. JW, PG, RG and PR were involved in patient monitoring and acquisition of clinical data. $J$ and $C A$ did the statistical analyses. TC wrote the paper. NM, CA, JL, JW, PG, RG and PR critically appraised the paper for its intellectual content. All authors read and approved the final manuscript.

\section{Competing interest}

The authors declare that they have no competing interests.

Consent for publication

Not applicable.

\section{Ethics approval and consent to participate}

Ethics approval was obtained from Ethics Review Committees of Faculty of Medicine, University of Colombo, National Hospital of Sri Lanka and Lady Ridgeway Hospital for Children. Written informed consent was obtained from either the patient or guardian.

\section{Publisher's Note}

Springer Nature remains neutral with regard to jurisdictional claims in published maps and institutional affiliations.

\section{Author details}

${ }^{1}$ Department of Pathophysiology, Eastern University, Colombo, Sri Lanka. ${ }^{2}$ Department of Microbiology, University of Sri Jayawardenapura, Nugegoda, Sri Lanka. ${ }^{3}$ Department of Community Medicine, University of Colombo, Colombo, Sri Lanka. ${ }^{4}$ Department of Paediatrics, University of Colombo, Colombo, Sri Lanka. ${ }^{5}$ National Hospital of Sri Lanka, Colombo, Sri Lanka. ${ }^{6}$ Lady Ridgeway Hospital for children, Colombo, Sri Lanka. ${ }^{7}$ Department of Clinical Medicine, Faculty of Medicine - University of Colombo, 25, Kynsey Road, Colombo 00800, Sri Lanka. 
Received: 8 September 2016 Accepted: 12 April 2017 Published online: 24 April 2017

\section{References}

1. Bale Jr JF. Virus and Immune-Mediated Encephalitides: Epidemiology, Diagnosis, Treatment, and Prevention. Pediatr Neurol. 2015;53(1):3-12.

2. Swanson 2nd PA, McGavern DB. Viral diseases of the central nervous system. Curr Opin Virol. 2015;11:44-54.

3. Steiner I, Budka H, Chaudhuri A, Koskiniemi M, Sainio K, Salonen O, et al. Viral encephalitis: a review of diagnostic methods and guidelines for management. Eur J Neurol. 2005;12(5):331-43.

4. Granerod J, Ambrose HE, Davies NW, Clewley JP, Walsh AL, Morgan D, et al. Causes of encephalitis and differences in their clinical presentations in England: a multicentre, population-based prospective study. Lancet Infect Dis. 2010;10(12):835-44.

5. Koskiniemi M, Rautonen J, Lehtokoski-Lehtiniemi E, Vaheri A. Epidemiology of encephalitis in children: a 20-year survey. Ann Neurol. 1991;29(5):492-7.

6. Kupila L, Vuorinen T, Vainionpaa R, Hukkanen V, Marttila RJ, Kotilainen P. Etiology of aseptic meningitis and encephalitis in an adult population. Neurology. 2006;66(1):75-80.

7. Sarkari NB, Thacker AK, Barthwal SP, Mishra VK, Prapann S, Srivastava D, et al. Japanese encephalitis (JE). Part I: clinical profile of 1,282 adult acute cases of four epidemics. J Neurol. 2012;259(1):47-57.

8. Kramer LD, Styer LM, Ebel GD. A global perspective on the epidemiology of West Nile virus. Annu Rev Entomol. 2008;53:61-81.

9. Paton NI, Leo YS, Zaki SR, Auchus AP, Lee KE, Ling AE, et al. Outbreak of Nipah-virus infection among abattoir workers in Singapore. Lancet. 1999; 354(9186):1253-6.

10. Chadha MS, Arankalle VA, Jadi RS, Joshi MV, Thakare JP, Mahadev PV, et al. An outbreak of Chandipura virus encephalitis in the eastern districts of Gujarat state, India. AmJTrop Med Hyg. 2005;73(3):566-70.

11. Venkatesan A, Tunkel AR, Bloch KC, Lauring AS, Sejvar J, Bitnun A, et al. Case definitions, diagnostic algorithms, and priorities in encephalitis: consensus statement of the international encephalitis consortium. Clin Infect Dis. 2013; 57(8):1114-28

12. Lakeman FD, Whitley RJ. Diagnosis of herpes simplex encephalitis: application of polymerase chain reaction to cerebrospinal fluid from brainbiopsied patients and correlation with disease. National Institute of Allergy and Infectious Diseases Collaborative Antiviral Study Group. J Infect Dis. 1995;171(4):857-63.

13. Mori C, Takahara R, Toriyama T, Nagai T, Takahashi M, Yamanishi K Identification of the Oka strain of the live attenuated varicella vaccine from other clinical isolates by molecular epidemiologic analysis. J Infect Dis. 1998; 178(1):35-8

14. Wagner HJ, Bein G, Bitsch A, Kirchner H. Detection and quantification of latently infected $B$ lymphocytes in Epstein-Barr virus-seropositive, healthy individuals by polymerase chain reaction. J Clin Microbiol. 1992;30(11):2826-9.

15. Zweygberg Wirgart B, Brytting M, Linde A, Wahren B, Grillner L. Sequence variation within three important cytomegalovirus gene regions in isolates from four different patient populations. J Clin Microbiol. 1998;36(12):3662-9.

16. Lanciotti RS, Calisher CH, Gubler DJ, Chang GJ, Vorndam AV. Rapid detection and typing of dengue viruses from clinical samples by using reverse transcriptase-polymerase chain reaction. J Clin Microbiol. 1992;30(3):545-51.

17. Lohitharajah J, Malavige GN, Chua AJ, Ng ML, Arambepola C, Chang T. Emergence of human West Nile Virus infection in Sri Lanka. BMC Infect Dis. 2015;15:305.

18. Peiris JS, Amerasinghe FP, Amerasinghe PH, Ratnayake CB, Karunaratne $\mathrm{SH}$, Tsai TF. Japanese encephalitis in Sri Lanka-the study of an epidemic: vector incrimination, porcine infection and human disease. Trans R Soc Trop Med Hyg. 1992;86(3):307-13

19. Cowan FM, French RS, Mayaud P, Gopal R, Robinson NJ, de Oliveira SA, et al. Seroepidemiological study of herpes simplex virus types 1 and 2 in Brazil, Estonia, India, Morocco, and Sri Lanka. Sex Transm Infect. 2003;79(4):286-90.

20. Koskiniemi M, Piiparinen H, Mannonen L, Rantalaiho T, Vaheri A. Herpes encephalitis is a disease of middle aged and elderly people: polymerase chain reaction for detection of herpes simplex virus in the CSF of 516 patients with encephalitis. The Study Group. J Neurol Neurosurg Psychiatry. 1996;60(2):174-8.
21. Jeewandara C, Gomes L, Paranavitane SA, Tantirimudalige M, Panapitiya SS, Jayewardene A, et al. Change in Dengue and Japanese Encephalitis Seroprevalence Rates in Sri Lanka. PLoS One. 2015;10(12):e0144799.

22. Solbrig MV, Perng GC. Current neurological observations and complications of dengue virus infection. Curr Neurol Neurosci Rep. 2015;15(6):29.

23. Withana M, Rodrigo C, Chang T, Karunanayake P, Rajapakse S. Dengue fever presenting with acute cerebellitis: a case report. BMC Res Notes. 2014;7:125.

24. Graus F, Titulaer MJ, Balu R, Benseler S, Bien CG, Cellucci T, et al. A clinical approach to diagnosis of autoimmune encephalitis. Lancet Neurol. 2016; 15(4):391-404.

25. Wanigasinghe J, Chang T, Vincent A. Treatment-responsive, reversible, autoimmune encephalitis in a child. Ceylon Med J. 2012;57(2):90-1.

26. Tyler KL, Pape J, Goody RJ, Corkill M, Kleinschmidt-DeMasters BK. CSF findings in 250 patients with serologically confirmed West Nile virus meningitis and encephalitis. Neurology. 2006;66(3):361-5.

27. Liyanage NP, Fernando S, Malavige GN, Mallikahewa R, Sivayogan S, Jiffry MT, et al. Seroprevalence of varicella zoster virus infections in Colombo district, Sri Lanka. Indian J Med Sci. 2007;61(3):128-34.

28. Malavige GN, Jones L, Kamaladasa SD, Wijewickrama A, Seneviratne SL, Black AP, et al. Viral load, clinical disease severity and cellular immune responses in primary varicella zoster virus infection in Sri Lanka. PLoS One. 2008:3(11):e3789.

29. Britton PN, Khoury L, Booy R, Wood N, Jones CA. Encephalitis in Australian children: contemporary trends in hospitalisation. Arch Dis Child. 2016;101(1):51-6.

30. Peiris JS, Dittus WP, Ratnayake CB. Seroepidemiology of dengue and other arboviruses in a natural population of toque macaques (Macaca sinica) at Polonnaruwa, Sri Lanka. J Med Primatol. 1993;22(4):240-5.

31. Venkatesan A. Epidemiology and outcomes of acute encephalitis. Curr Opin Neurol. 2015;28(3):277-82.

\section{Submit your next manuscript to BioMed Central and we will help you at every step:}

- We accept pre-submission inquiries

- Our selector tool helps you to find the most relevant journal

- We provide round the clock customer support

- Convenient online submission

- Thorough peer review

- Inclusion in PubMed and all major indexing services

- Maximum visibility for your research

Submit your manuscript at www.biomedcentral.com/submit 